\title{
Epidermal Growth Factor Attenuated the Expression of Inflammatory Cytokines in Human Epidermal Keratinocyte Exposed to Propionibacterium acnes
}

\author{
Ji Min Kim, Jung Eun Choo, Heun Joo Lee ${ }^{1}$, Ki Nam Kim, Sung Eun Chang ${ }^{1}$ \\ Life Science Research Institute, Daewoong Pharmaceutical Co., Ltd., Yongin, ${ }^{1}$ Department of Dermatology, Asan Medical Center, \\ University of Ulsan College of Medicine, Seoul, Korea
}

Background: While the beneficial effects of topical epidermal growth factor (EGF) on wound healing have been repeatedly reported, there are few reports about the effects of EGF on inflammatory skin diseases including acne. Objective: To clarify the effects of EGF on acne, it was investigated whether recombinant human EGF (rhEGF) signalling can affect Propionibacterium acnes-induced cytokine expression in human epidermal keratinocytes. Methods: The cultured normal human epidermal keratinocytes (NHK) were co-treated with $P$. acnes and rhEGF, and mRNA levels of interleukin (IL)- $1 \alpha$, IL-8 and tumor necrosis factor (TNF)- $\alpha$; toll-like receptor 2 (TLR2); and nuclear factor kappa B (NF- $\kappa \mathrm{B}$ ) were determined. Specific enzyme-linked immunosorbent assay kits were used to measure the IL- $1 \alpha$, IL- 8 and TLR2 expression as well as the NF- $\kappa \mathrm{B}$ activation in $P$. acnes and rhEGF-treated NHK. After infecting the cultured NHK with live $P$. acnes, an increased expression of IL-1 $\alpha, \mathrm{IL}-8$ and TNF- $\alpha$ was detected, which was prevented by rhEGF co-treatment. Results: TLR2 and NF- $\kappa$ B activity increased after $P$. acnes treatment, and rhEGF treatment decreased TLR2 expression and NF- $\kappa \mathrm{B}$ activity dose-dependently. The inhibition of EGF receptor by gefitinib attenuated the inhibitory

Received June 1, 2017, Revised July 26, 2017, Accepted for publication August 1, 2017

Corresponding author: Sung Eun Chang, Department of Dermatology, Asan Medical Center, University of Ulsan College of Medicine, 88 Olympic-ro 43-gil, Songpa-gu, Seoul 05505, Korea. Tel: 82-2-3010-3467, Fax: 82-2-486-7831, E-mail: csesnumd@gmail.com

This is an Open Access article distributed under the terms of the Creative Commons Attribution Non-Commercial License (http://creativecommons. org/licenses/by-nc/4.0) which permits unrestricted non-commercial use, distribution, and reproduction in any medium, provided the original work is properly cited.

Copyright (c) The Korean Dermatological Association and The Korean Society for Investigative Dermatology effect of rhEGF on these increased expressions of proinflammatory cytokines and TLR2 and activity of NF- $\kappa \mathrm{B}$ in NHK stimulated by $P$. acnes. Conclusion: These results suggest that EGF attenuated $P$. acnes-induced inflammatory responses, at least in part, through the modulation of TLR2 signalling, and the topical application of rhEGF may be beneficial to relieve the inflammatory reactions of acne. (Ann Dermatol 30(1) 54 63, 2018)

\section{-Keywords-}

Acne vulgaris, Epidermal growth factor, Propionibacterium acnes, Toll-like receptor 2

\section{INTRODUCTION}

Acne is one of the most common inflammatory skin diseases with accumulated data regarding the pathogenesis of acne but the treatments are still unsatisfactory.

A related family of toll-like receptors (TLRs) is widely expressed in mammalian tissues, particularly epithelia, and a growing body of research indicates the importance of innate immunity as defence response in skin diseases ${ }^{1}$. The TLR family is composed of a group of cell surface receptors that are important for both innate and acquired immune responses against invading microorganisms ${ }^{2}$. Pathogen-associated molecular patterns bind to TLRs in order to induce various inflammatory reactions mediated by nuclear factor kappa B (NF- $\kappa$ B) and mitogen-activated protein kinase (MAPK) pathways ${ }^{3}$.

Propionibacterium acnes, a commensal Gram-positive anaerobic rod is considered to be the primary bacterium implicated in acne development ${ }^{4}$. However, successful antibiotic treatment may not result from a reduction of 
bacterial numbers. The antibiotics typically used in the management of acne, tetracyclines, have additional anti-inflammatory actions independent of microbial killing. $P$. acnes has role in inciting inflammation in acne, thus more targeted therapeutic interventions may be necessary. $P$. acnes triggers inflammatory cytokine responses in acne by activation of TLR2 indicating that TLR2 could be a target for treatment of acne. For one example, oral isotretinoin treatment normalized exaggerated TLR2-mediated innate immune responses in acne patients. $P$. acnes also activates inflammatory molecules such as interleukin (IL)- $1 \alpha$, IL-8 and tumor necrosis factor (TNF)- $\alpha$ via the TLR2 signalling pathway ${ }^{5}$. The release of proinflammatory cytokines mediated through TLR2 has a harmful effect to acne as it promotes inflammation and tissue destruction ${ }^{6}$. Several reports have shown that TLRs communicate with the epidermal growth factor receptor (EGFR) via epithelial signalling to produce certain innate immune responses ${ }^{7}$. However, the effect of epidermal growth factor (EGF) and EGFR signalling on the TLR2 associated pathway in acne and other inflammatory skin diseases is unknown.

The EGFR signalling pathway has a critical role in skin development and homeostasis. Epidermal keratinocytes are a rich source of EGFR ligands including EGF, transforming growth factor alpha (TGF- $\alpha$ ), amphiregulin, heparin-binding EGF (HB-EGF) and epiregulin ${ }^{8}$. It is well known that EGF is involved in cutaneous wound healing through the stimulation, proliferation and migration of keratinocytes, endothelial cells and fibroblasts, thus facilitating epidermal and dermal regeneration ${ }^{9}$. Moreover, the local administration of EGF induced remission in patients with ulcerative colitis ${ }^{10}$. Interestingly, EGF was also involved in down-modulation of inflammation. In their report, EGFR signalling blunted allergen-induced IL- 6 production and T-helper 17 cell responses in the skin, and attenuated the development and relapse of atopic dermatitis in animal study.

Although the important roles of EGF in wound healing are well known ${ }^{11}$, there are few reports about the effects of EGF and EGFR on inflammatory skin diseases including acne and human defence response. Considering that topical EGF preparation often has been used to improve acne in dermatological clinical setting and cosmetics including enough concentration of recombinant human EGF (rhEGF) improved the clinical severity of mild to moderate acne in one report ${ }^{12}$. Moreover, EGF receptor inhibitors which are often used to treat various cancers inevitably induced acneiform eruption in the skin as adverse effects of the drugs.

Thus, we investigated whether administration of rhEGF can affect $P$. acnes-induced events in normal human epi- dermal keratinocytes (NHK). Also, we hypothesized that EGF might downregulate TLR2 signalling pathway associated proinflammatory responses induced by $P$. acnes.

\section{MATERIALS AND METHODS}

\section{Reagents}

P. acnes (KCTC 3314) was obtained from the Korean Collection for Type Cultures (KCTC, Daejeon, Korea). rhEGF (Daewoong Pharmaceutical Co., Ltd., Seoul, Korea) was used in this study. Nicotinamide was purchased from Sigma-Aldrich (St. Louis, MI, USA). Gefitinib was purchased from AstraZeneca Corporation (San Diego, CA, USA).

\section{Cell culture}

NHK (Thermo Fisher Scientific, Waltham, MA, USA) were cultured in EpiLife Medium (Thermo Fisher Scientific) with human keratinocyte growth supplement (HKGS, Thermo Fisher Scientific). Before reagent treatment, the cells were cultured in EpiLife medium (Thermo Fisher Scientific) for starvation overnight. Cells were maintained in a humidified atmosphere of $5 \% \mathrm{CO}_{2}$ at $37^{\circ} \mathrm{C}$, and the medium was replaced every two days. To induce inflammatory cytokines and TLR2 signalling, NHK were stimulated by 10 multiplicity of infection (MOI) $P$. acnes. The reagents were treated to NHK with $10 \mathrm{MOI} P$. acnes.

\section{Real-time reverse-transcription-quantitative polymerase chain reaction}

After treatment, the total ribonucleic acid (RNA) was extracted from cells using the ReliaPrep ${ }^{T M}$ RNA Cell Miniprep System (Promega, Madison, WI, USA), and $1 \mu \mathrm{g}$ of the total RNA was converted to cDNA using the TaKaRa RNA PCR Kit ver. 2.1 (TaKaRa Bio Inc., Shiga, Japan), under the following reaction conditions: $45^{\circ} \mathrm{C}$ for $45 \mathrm{~min}$ and $95^{\circ} \mathrm{C}$ for $5 \mathrm{~min}$. Probes were obtained from Applied Biosystems (Foster City, CA, USA) as Assays-onDemand $^{\mathrm{TM}}$ Gene Expression Assays (glyceraldehyde-3phosphate dehydrogenase [GAPDH]: Hs02758991_g1, IL-1 $\alpha$ : Hs00174092_m1, IL-8: Hs00174103_m1, TNF- $\alpha$ : Hs01113624_m1, TLR2: Hs01872448_s1, NF- $\kappa$ B: Hs00 765730_m1, p38 $\alpha$ : Hs01051152_m1). Reactions were carried out on the $\mathrm{ABI}$ StepOnePlus ${ }^{\mathrm{T}}{ }^{-}$(Applied Biosystems), and relative transcription levels were determined by GAPDH as the reference gene. The data were analysed by using the ABI StepOnePlus ${ }^{\text {TM }}$ software (Applied Biosystems).

\section{Enzyme-linked immunosorbent assay}

The secretion of IL- $1 \alpha$, IL- 8 and TNF- $\alpha$ in the 48 hours supernatants of reagent-treated or untreated control was determined using specific enzyme-linked immunosorbent 
assay (ELISA) kits as instructed by the manufacturer. The IL-1 $\alpha$, IL-8 and TNF- $\alpha$ ELISA kits were obtained from R\&D Systems (Minneapolis, MN, USA). After treatment, whole-cell lysates were collected by using a cell lysis buffer (Cell Signaling Technology, Danvers, MA, USA). The concentration of TLR2 in the cell lysates was then measured by using a specific ELISA kit (R\&D Systems).

\section{NF- $\kappa B(p 65)$ activation assay}

To examine transcription factor activity, nuclear extracts were collected using a nuclear extraction kit (Cayman, Ann Arbor, MI, USA) in the reagent-treated or untreated NHK for 48 hr. Protein concentrations were determined with a Bio-Rad reagent (Bio-Rad Laboratories, Hercules, $\mathrm{CA}$, USA). The activation of NF- $\kappa \mathrm{B}$ (p65) transcription factor was detected by using an NF- $\kappa \mathrm{B}$ (p65) transcription factor assay kit (Cayman). Briefly, $10 \mu \mathrm{g}$ of nuclear proteins were added to the wells with a complete transcription factor buffer and incubated overnight at $4{ }^{\circ} \mathrm{C}$. Blank wells, a positive control, and nonspecific binding samples were also included on the plate. After that, NF- $\kappa \mathrm{B}$ binding was detected by incubating with monoclonal and secondary antibodies directed against the NF- $\kappa \mathrm{B}$ p65 subunit. Reaction was quantified at $450 \mathrm{~nm}$. The percent change in the activity of each test sample relative to the average of untreated samples was determined.

A

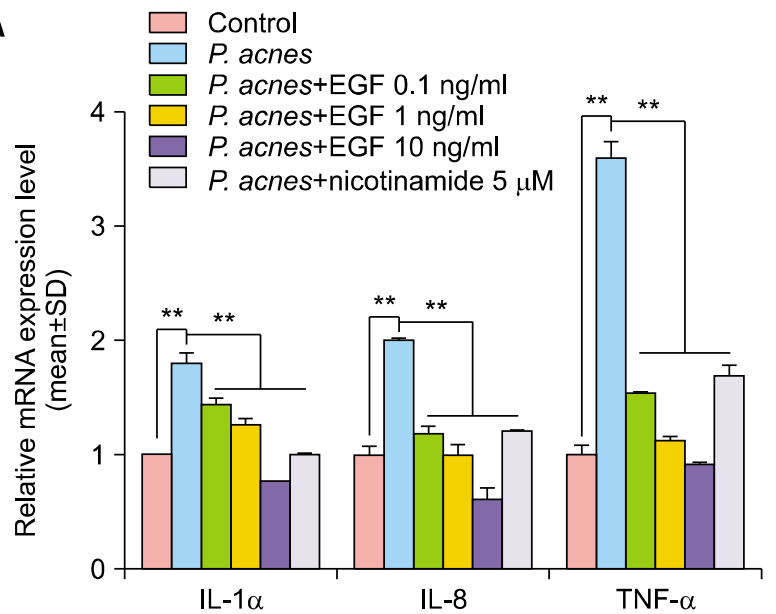

\section{Statistical analysis}

All experiments were carried out in triplicate, and the results are exposed as mean \pm standard deviation. $p$-values $<0.05$ were considered statistically significant. One-way analysis of variance with Dunnett's posttest was performed using GraphPad Prism ver. 7 (GraphPad Software, San Diego, CA, USA).

\section{RESULTS}

\section{Downregulation of rhEGF on the expression of cytokines induced by $P$. ances}

To investigate our hypothesis, we treated NHK with 10 MOI $P$. acnes and various concentrations of rhEGF for 6 and 48 hours. After that, we confirmed the mRNA and protein expressions of proinflammatory cytokines such as IL- $1 \alpha$, IL- 8 and TNF- $\alpha$ through real-time quantitative polymerase chain reaction (RT-qPCR) and by using ELISA kits. The mRNA expression of IL- $1 \alpha$, IL- 8 and TNF- $\alpha$ was induced by $P$. acnes and was downregulated by rhEGF in a concentration-dependent manner (Fig. 1A). Moreover, in a concentration-dependent manner, rhEGF inhibited the protein expression of IL- $1 \alpha$, IL- 8 and TNF- $\alpha$ increased by P. acnes (Fig. 1B). Nicotinamide of $5 \mu \mathrm{M}$, which was used as a positive control, reduced the mRNA and protein ex-

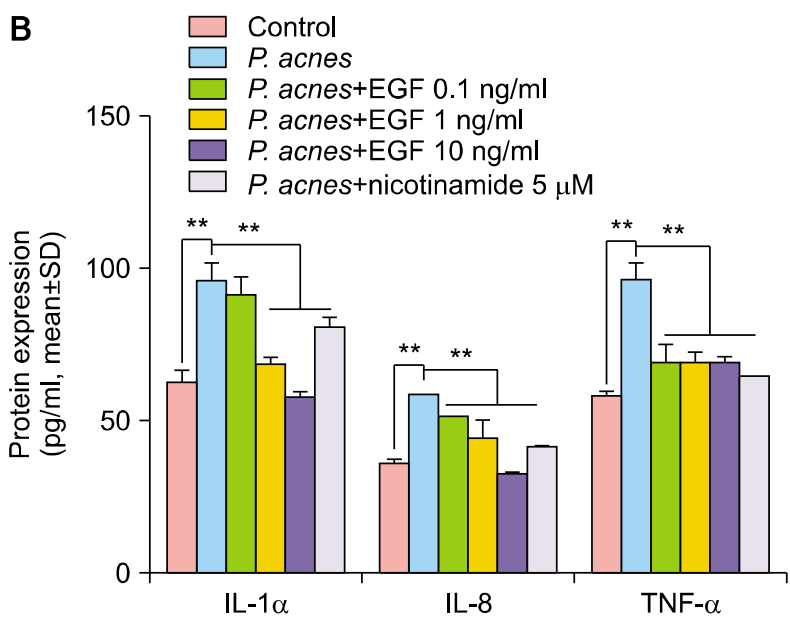

Fig. 1. The effect of recombinant human epidermal growth factor (rhEGF) on interleukin (IL)-1 $\alpha$, IL-8 and tumor necrosis factor (TNF)- $\alpha$ expression in Propionibacterium acnes-stimulated normal human epidermal keratinocytes (NHK). NHK were stimulated with 10 multiplicity of infection (MOI) $P$. acnes for 6 and 48 hours in the presence of $0.1,1$ or $10 \mathrm{ng} / \mathrm{ml}$ rhEGF, or $5 \mu \mathrm{M}$ nicotinamide. The messenger ribonucleic acid (mRNA) expression levels of IL-1 $\alpha$, IL-8 and TNF- $\alpha$ were analysed through real-time quantitative reverse transcription-polymerase chain reaction (RT-qPCR). The secretion of IL- $1 \alpha$, IL- 8 and TNF- $\alpha$ was determined by using specific enzyme-linked immunosorbent assay (ELISA) kits. (A) The mRNA expression of IL-1 $\alpha$, IL-8 and TNF- $\alpha$ induced by $P$. acnes was inhibited by rhEGF in a concentration-dependent manner. $5 \mu \mathrm{M}$ nicotinamide, which was used as a positive control, was also observed to reduce the mRNA levels of IL-1 $\alpha$, IL-8 and TNF- $\alpha$. (B) Similar to the gene result, in a concentration-dependent manner, rhEGF downregulated the protein expression of IL- $1 \alpha$, IL- 8 and TNF- $\alpha$ induced by $P$. acnes. Results are presented as mean \pm standard deviation (SD), representative of three separate experiments. Asterisks indicate statistically significant differences $(* * p<0.01)$. 
A
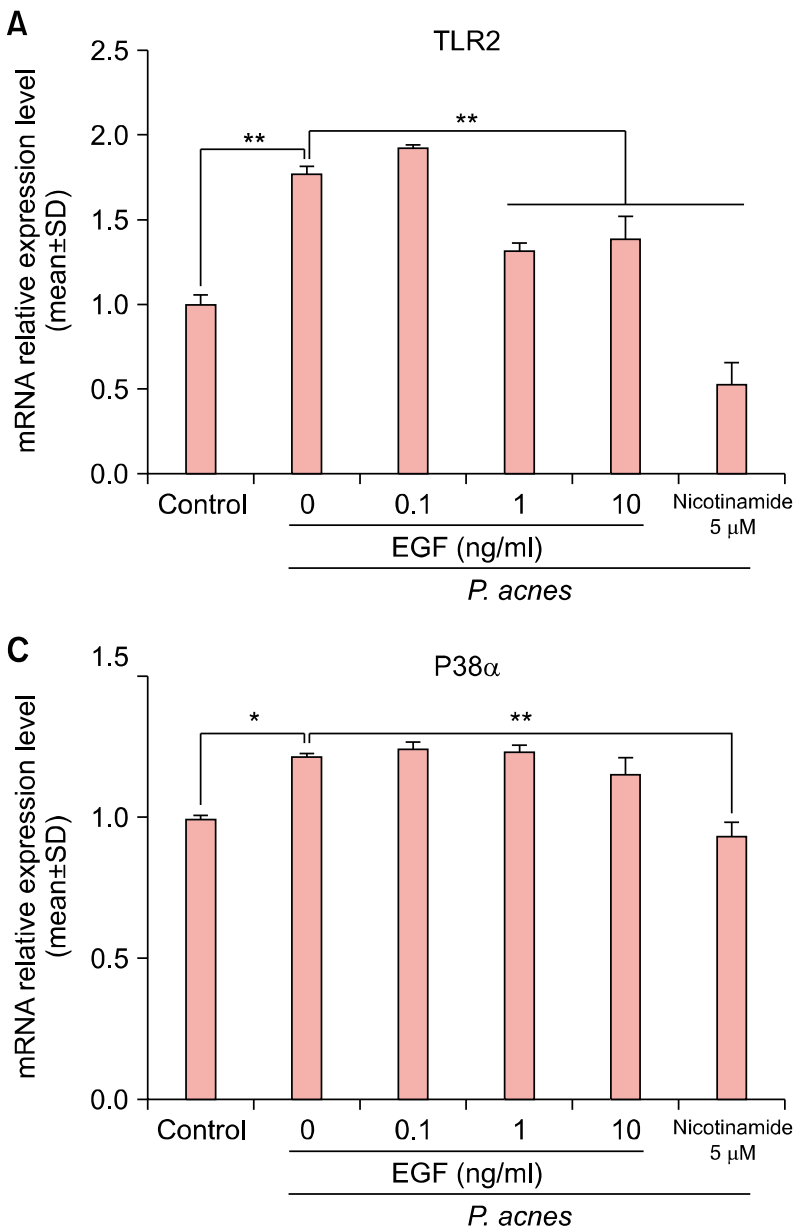

E

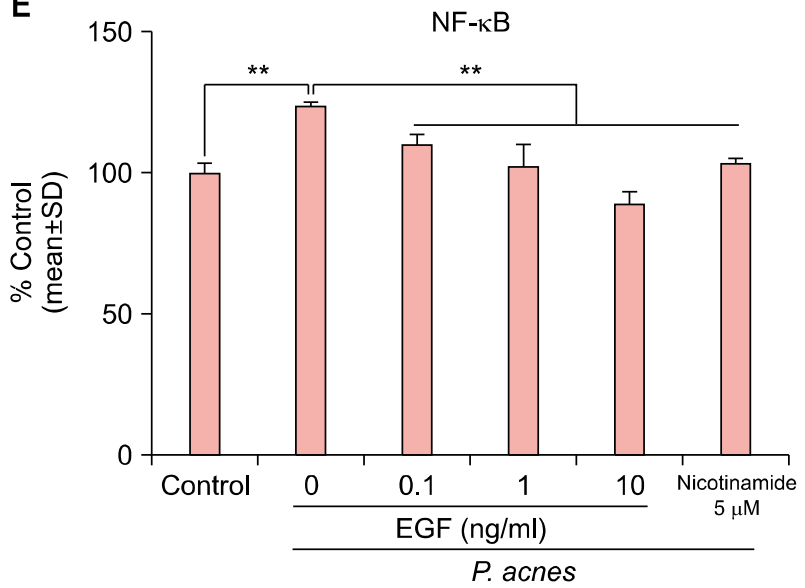

B
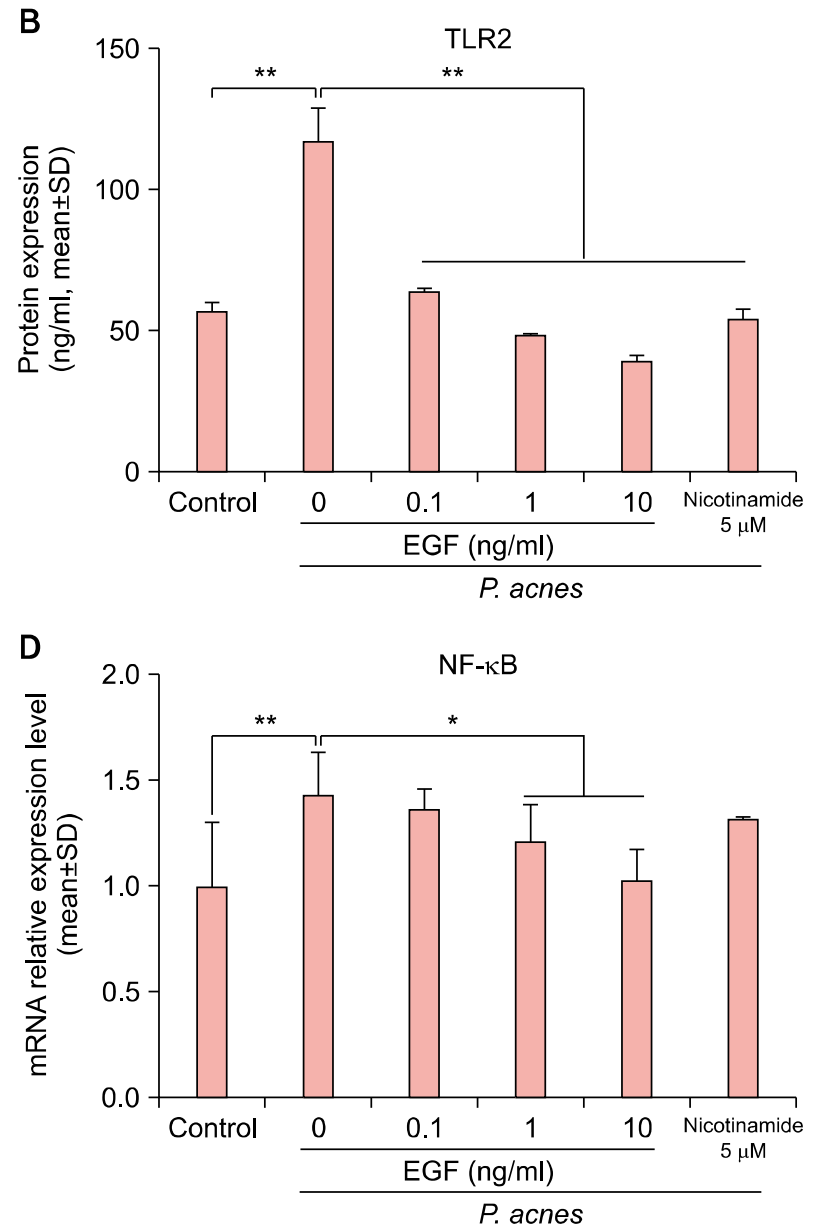

Fig. 2. The Propionibacterium acnes-induced expression of toll-like receptor 2 (TLR2) and nuclear factor kappa B (NF- $\kappa$ B) activity were reduced by recombinant human epidermal growth factor (rhEGF). Normal human epidermal keratinocytes (NHK) were stimulated with 10 multiplicity of infection (MOI) P. acnes for 6 and 48 hours in the presence of $0.1,1$, or $10 \mathrm{ng} / \mathrm{ml}$ rhEGF, or $5 \mu \mathrm{M}$ nicotinamide. The messenger ribonucleic acid (mRNA) expression levels of TLR2, P38 $\alpha$ and NF- $\kappa$ B were analysed through real-time quantitative reverse transcription-polymerase chain reaction (RT-qPCR). The protein expression of TLR2 and NF- $\kappa$ B activity were determined by using specific enzyme-linked immunosorbent assay (ELISA). (A, B) The gene and protein of TLR2 in $P$. acnes-stimulated NHK was inhibited by rhEGF and $5 \mu \mathrm{M}$ nicotinamide. (C, D) In $P$. acnes-stimulated NHK, the mRNA expression levels of NF- $\kappa \mathrm{B}$ were downregulated by rhEGF in a concentration-dependent manner, but not P38 $\alpha$. In contrast, $5 \mu \mathrm{M}$ nicotinamide inhibited the mRNA expression levels of P38 $\alpha$ in $P$. acnes-treated NHK, but not NF- $\kappa \mathrm{B}$. (E) Similar to the gene result, the $P$. acnes-induced activity of NF- $\kappa \mathrm{B}$ was inhibited by rhEGF in a concentration-dependent manner. Results are presented as mean \pm standard deviation (SD), representative of three separate experiments. Asterisks indicate statistically significant differences $(* p<0.05, * * p<0.01)$. 
pressions of proinflammatory cytokines including IL-1 $\alpha$, IL-8, and TNF- $\alpha$ (Fig. 1).

\section{Regulation of rhEGF on the TLR2 expression in NHK stimulated by $P$. ances}

Next, we assessed the TLR2 gene and protein expression in NHK when $P$. acnes and various concentrations of rhEGF were added to the culture for 6 and 48 hours through RT-qPCR and by using ELISA kits. As expected, 1 and $10 \mathrm{ng} / \mathrm{ml} \mathrm{rhEGF}$ as well as $5 \mu \mathrm{M}$ nicotinamide inhibited the TLR2 gene expression in NHK stimulated by $P$. acnes (Fig. 2A). Moreover, the protein expression of TLR2 increased by $P$. acnes was inhibited by rhEGF and nic- otinamide (Fig. 2B).

\section{Regulation of rhEGF on the NF- $\kappa \mathrm{B}$ activity in $P$. acnes treated NHK}

Then, to determine which transcription factors are involved in these results, we confirmed the mRNA expression of NF- $\kappa \mathrm{B}$ and P38 $\alpha$. NF- $\kappa \mathrm{B}$ expression, but not P38 $\alpha$ RNA expression, was downregulated by 1 and $10 \mathrm{ng} / \mathrm{ml}$ of rhEGF (Fig. 2C, D). On the other hand, P38 $\alpha$ RNA expression, but not NF- $\kappa \mathrm{B}$ expression, was downregulated by 5 $\mu \mathrm{M}$ nicotinamide in $P$. acnes-treated NHK (Fig. 2C, D). Similarly, with gene expression, the resulting NF- $\kappa \mathrm{B}$ activity was also inhibited by rhEGF in a concentration-de-
A

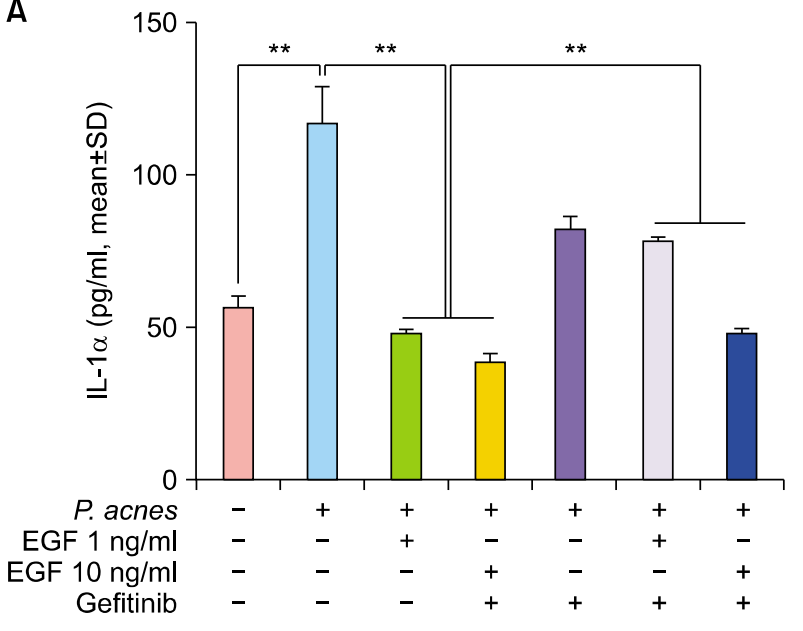

C

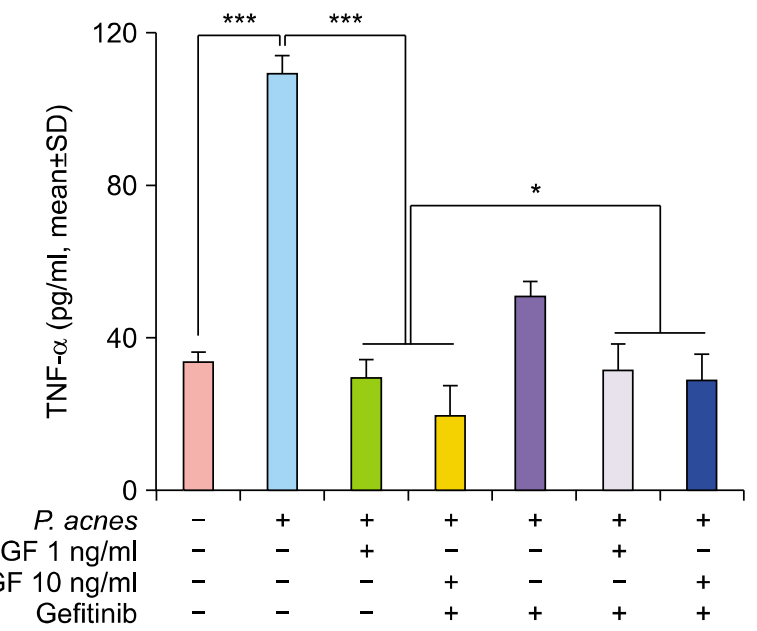

B

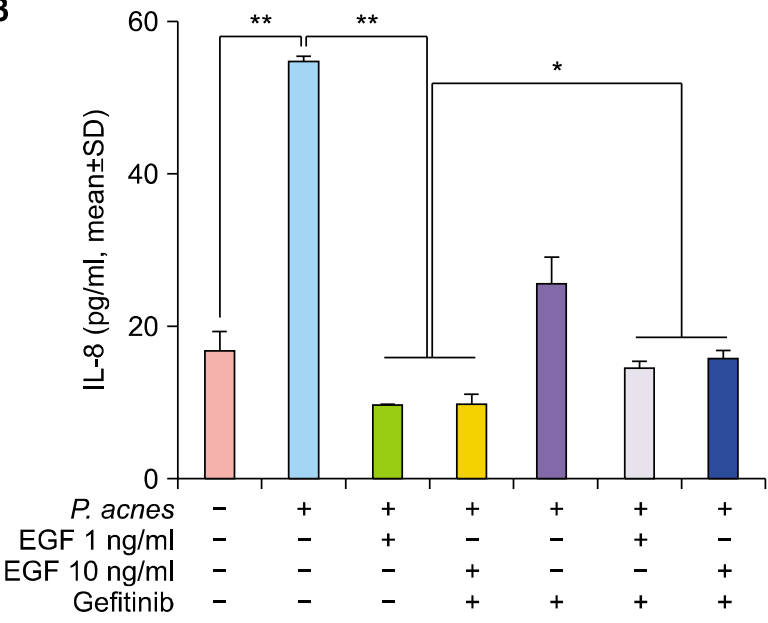

Control

$P$. acnes

$P$. acnes EGF $1 \mathrm{ng} / \mathrm{m}$

P. acnes EGF $10 \mathrm{ng} / \mathrm{ml}$

$P$. acnes gefitinib

$P$. acnes gefitinib EGF $1 \mathrm{ng} / \mathrm{m}$

P. acnes gefitinib EGF $10 \mathrm{ng} / \mathrm{ml}$

Fig. 3. The effects of the inhibition of interleukin (IL)- $1 \alpha$, IL- 8 and tumor necrosis factor (TNF)- $\alpha$ expression on recombinant human epidermal growth factor (rhEGF) attenuated by gefitinib. Normal human epidermal keratinocytes (NHK) were treated with Propionibacterium acnes in the presence or absence of 1 or $10 \mathrm{ng} / \mathrm{ml}$ rhEGF for 48 hours, with pretreatment with $100 \mathrm{nM}$ gefitinib, which was a selective epidermal growth factor (EGF) receptor inhibitor. Then, stimulation supernatants were collected, and the protein expressions of IL-1, IL-8 and TNF- $\alpha$ were determined by using specific enzyme-linked immunosorbent assay. Gefitinib of $100 \mathrm{nM}$ attenuated the inhibitor effect of rhEGF on IL-1 $\alpha$ (A), IL-8 (B) and TNF- $\alpha$ (C) in $P$. acnes-treated NHK. Results are presented as mean \pm standard deviation (SD), representative of three separate experiments. Asterisks indicate statistically significant differences $(* p$ $<0.05, * * p<0.01, * * * p<0.001)$. 
A

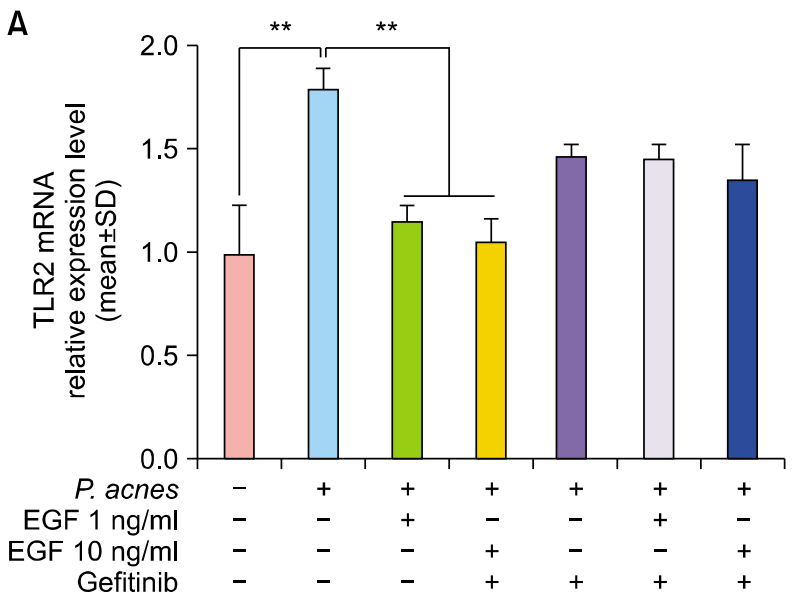

C

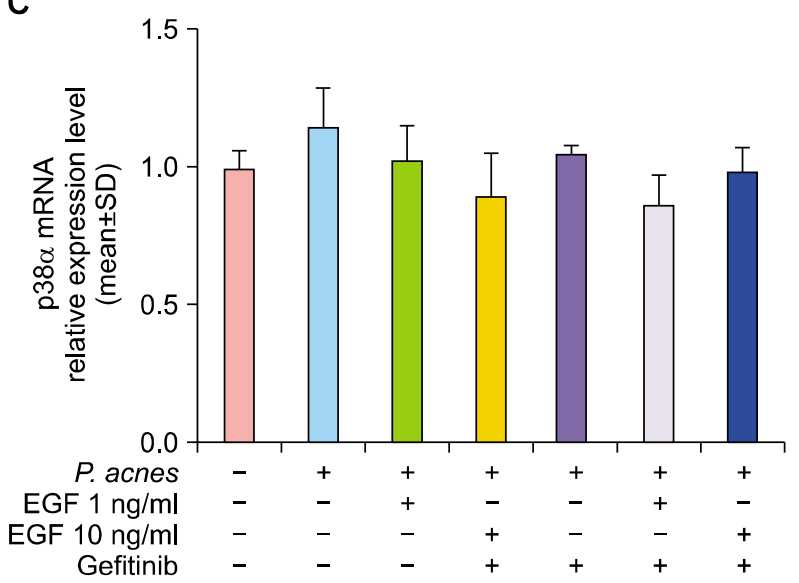

$\mathrm{E}$

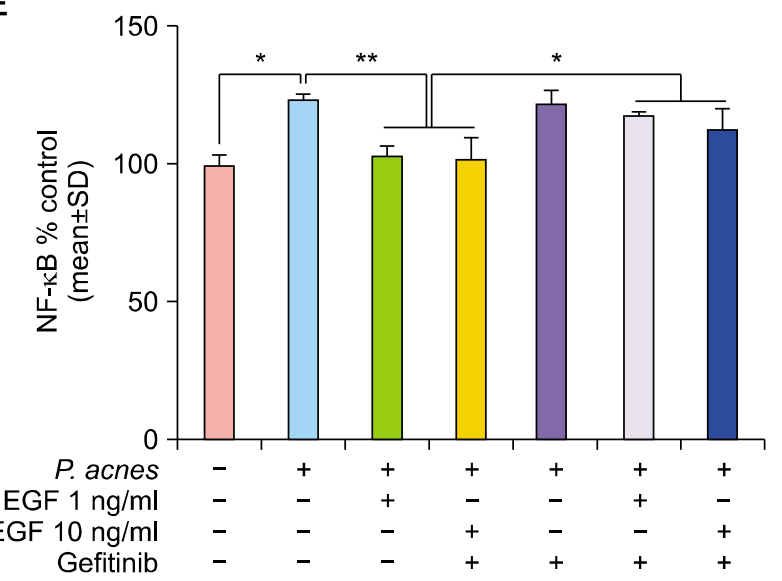

B

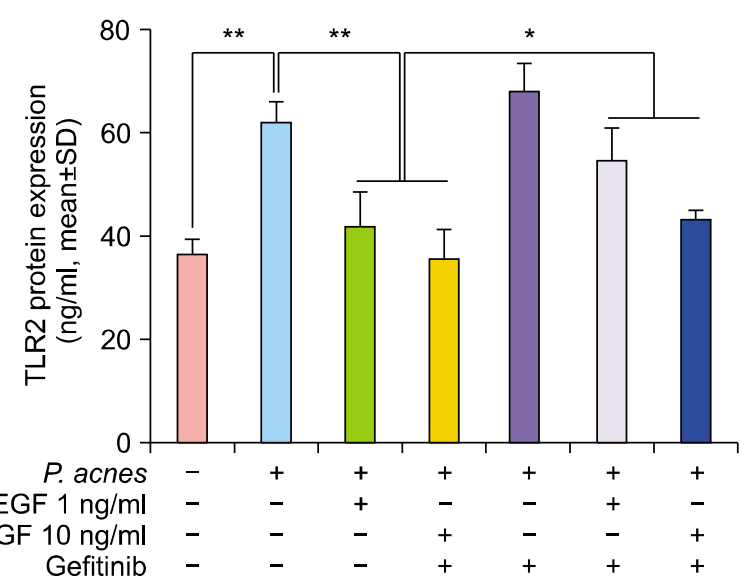

D

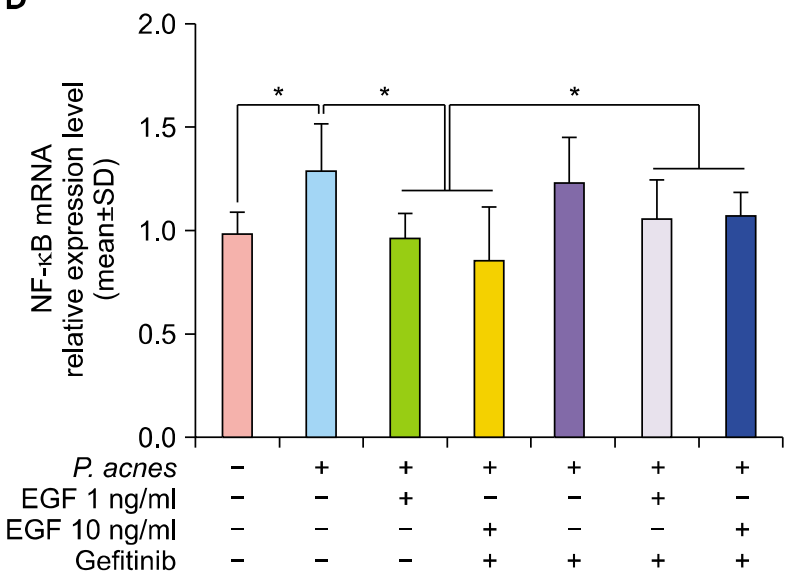

Fig. 4. Gefitinib reduced the inhibition effect of recombinant human epidermal growth factor (rhEGF) on toll-like receptor 2 (TLR2) and nuclear factor kappa B (NF- $\kappa \mathrm{B})$ activity increased by Propionibacterium acnes. Normal human epidermal keratinocytes (NHK) were treated with $P$. acnes in the presence or absence of 1 or $10 \mathrm{ng} / \mathrm{ml}$ rhEGF for 6 and 48 hours, with pretreatment with 100 $\mathrm{nM}$ gefitinib. After treatment, the total ribonucleic acid (RNA) was prepared from the cells, and the relative gene expressions of TLR2, P38 $\alpha$ and NF- $\kappa$ B were analysed through real-time quantitative reverse transcription-polymerase chain reaction (RT-qPCR); then, the total protein was collected from the cells, and the protein expression of TLR2 was detected by using enzyme-linked immunosorbent assay (ELISA). To assess NF- $\kappa$ B activity, nuclear protein was collected by using nuclear extraction kits, and a specific ELISA kit was used for measuring NF- $\kappa$ B activity. (A, B) TLR2 gene and protein expression was inhibited by 1 and $10 \mathrm{ng} / \mathrm{ml}$ rhEGF, and was reduced by $100 \mathrm{nM}$ gefitinib in $P$. acnes-treated NHK. (C) Gefitinib and rhEGF did not affect the P38 $\alpha$ mRNA expression level in $P$. acnes-stimulated NHK. The inhibition effect of rhEGF on gene expression (D) and NF- $\kappa$ B activity (E) was inhibited by $100 \mathrm{nM}$ gefitinib. Results are presented as mean \pm standard deviation (SD), representative of three separate experiments. Asterisks indicate statistically significant differences $(* p<0.05, * * p<0.01)$. 
pendent manner in P. acnes-treated NHK (Fig. 2E).

\section{Attenuation of EGF's regulatory effects on the proinflammatory cytokines, TLR2 expression and NF- $\kappa \mathrm{B}$ activity induced by $P$. acnes}

To confirm the inhibitory effects of rhEGF on proinflammatory cytokines and TLR2 expression, we used gefitinib, which is one of the EGFR inhibitors. NHK were treated with $100 \mathrm{nM}$ of gefitinib overnight. Then, they were treated with $10 \mathrm{MOI} P$. acnes as well as 1 and 10 $\mathrm{ng} / \mathrm{ml}$ rhEGF for 48 hours. As shown in Fig. 3, the addition of gefitinib reversed the inhibitory effects of rhEGF on the protein expression of IL-1 $\alpha$, IL-8 and TNF- $\alpha$. Next, to investigate the effects of gefitinib on TLR2 expression, we estimated the TLR2 gene and protein expression in NHK treated with gefitinib and/or $10 \mathrm{MOI} P$. acnes and/or rhEGF. Interestingly, the TLR2 protein expression, but not the mRNA expression of TLR2, inhibited by rhEGF was partially recovered by $100 \mathrm{nM}$ gefitinib (Fig. 4A, B). Similarly, as shown in Fig. 2C, the mRNA expression levels of p38 $\alpha$ were not altered by rhEGF and gefitinib (Fig. $4 \mathrm{C})$. As expected, the mRNA expression of NF- $\kappa \mathrm{B}$ and $\mathrm{NF}-\kappa \mathrm{B}$ activity downregulated by rhEGF were again recovered by gefitinib (Fig. 4D, E).

\section{DISCUSSION}

Treatments for acne vulgaris target one of more of the steps in pathogenesis and may be administered topically or orally. The most widely used acne treatments are topical formulations. Nicotinamide, also known as niacinamide, is the amide derivative of vitamin B3. It has been used both topically and systemically in various cutaneous inflammatory disorders including acne vulgaris. Recent studies revealed that nicotinamide decreases the in vitro secretion of IL-8 in P. acnes induced keratinocytes and has an anti-inflammatory role via inhibition of lysosomal enzyme release and mast cell degranulation ${ }^{13}$. In this study, nicotinamide was used as a positive control and was used to compare the inhibition effect of rhEGF on inflammatory cytokines expression. As the results, rhEGF inhibited mRNA and protein expression of IL- $1 \alpha$, IL-8 and TNF- $\alpha$, similar to nicotinamide. These results suggest that EGF can also have potential role to be used as acne vulgaris treatment.

Although the role of EGF in the skin regeneration process, such as in wound healing, is well established, its role in innate immunity and inflammation is not well characterised. In this study, we demonstrated that EGF/EGFR signalling plays an important role in the regulation of inflammation and innate immune responses by inhibiting proinflam- matory cytokines including IL-1 $\alpha$, IL-8 and TNF- $\alpha$ through the suppression of NF- $\kappa \mathrm{B}$ and possible relation of TLR2$\mathrm{NF}-\kappa \mathrm{B}$ signalling in $P$. acnes-stimulated epidermal keratinocytes. The role of EGFR signalling in inflammation is contradictory depending on the reports. In psoriatic lesions, IL-8 gene expression was actively induced by EGFR ligands such as TGF- $\alpha$ and amphiregulin ${ }^{14}$. However, it is also reported that EGF treatment increased anti-inflammatory cytokine IL-13 transcription expression ${ }^{15}$. Moreover, EGFR ligands, such as TGF- $\alpha$, HB-EGF and amphiregulin downregulated the levels of $\mathrm{CCL} 2 /$ monocyte chemotactic protein-1, CCL5/regulated-on-activation normal T-cell expressed and chemoattraction CXC ligand 10/IP10 $0^{16,17}$.

In the present study, we demonstrated for the first time the dose-dependent reduction of the gene expression of proinflammatory cytokines, including IL-1 $\alpha$, IL-8 and TNF- $\alpha$, in rhEGF-treated NHK stimulated by $P$. acnes. In accordance with the gene expression data, the protein expression of cytokines measured using ELISA kits was markedly inhibited by rhEGF in $P$. acnes-induced epidermal keratinocytes. We also demonstrated that the expression of TLR2 and the activation of NF- $\kappa$ B were downregulated by rhEGF in $P$. acnes-treated NHK. From our results, we can suggest that EGF/EGFR signalling in bacteria-stimulated epidermal keratinocytes may help to reduce inflammatory responses by downregulating proinflammatory cytokines.

Large amounts of TLR2 have been found to be expressed on perifollicular and peribulbar macrophages in acne lesions $^{18}$. In addition, it has been shown that there is a positive correlation between the severity of acne lesions and the concentration of cells expressing TLR $2^{18}$. TLR signalling can be divided into two signalling pathways: MyD88-dependent and MyD88-independent pathways ${ }^{2,19}$. It is known that TLR2 uses a Myeloid differentiation primary response gene 88 (MyD88)-dependent signalling pathway ${ }^{20}$. When TLR2 recognizes lipoprotein or lipopolysaccharide (LPS), the signalling is initiated. MyD88 recruits the interleukin-1 receptor-associated kinase 1 family of proteins, and by sub-signalling the p50 and p65 of NF- $\kappa \mathrm{B}^{\prime} \mathrm{s}$ subunits are translocated into the nucleus. The activated NF$\kappa \mathrm{B}$ in the nucleus initiate the transcription of inflammatory cytokine genes ${ }^{20}$. TLR2 can recognise $P$. acnes peptidoglycan and lipoteichoic acid, and it is considered that $P$. acnes-induced innate immune response through the TLR2 signalling pathway, including NF- $\kappa \mathrm{B}$ activation in the cells of the pilosebaceous unit and infiltrating monocytes, contributes to acne pathogenesis ${ }^{21}$. NF- $\kappa \mathrm{B}$ is a protein group that regulates inflammatory response, the immune system, cell death, cell proliferation, and the differentiation of epithelial cells ${ }^{22}$. It controls the expression of various genes and forms the central axis of the intra- 
cellular signal transduction system. In particular, NF- $\kappa \mathrm{B}$ plays a role in the regulation of immune homeostasis and inflammation in the skin. Recent study revealed that insulin like growth factor- 1 increased inflammatory biomarkers via activating NF- $\kappa \mathrm{B}$ in cultured sebocytes ${ }^{23}$. According to An et al. $^{24}$, pyrrolidinecarbodithioic acid, which is a potent NF- $\kappa \mathrm{B}$ inhibitor, inhibited LPS-induced NF- $\kappa \mathrm{B}$ p65 subunit nuclear translocation as well as the up-regulation of TLR2, 4 and 9 mRNA expression in dendritic cell. That results mean that the NF- $\kappa$ B pathway is important in the regulation of TLR expression ${ }^{24}$. In addition to NF- $\kappa \mathrm{B}$ activation, TLR2 also activates MAPK signalling. In this signalling, p38 and c-Jun N-terminal kinase activation and finally Elk-1 and activator protein 1 are translocated into the nucleus ${ }^{25,26}$. In this study, rhEGF inhibits the expression and activity of NF- $\kappa \mathrm{B}$ induced by $P$. acnes but $\mathrm{P} 38 \alpha$ expression was not regulated by $P$. acnes and rhEGF in NHK. This result suggests that the immune responses induced by $P$. acnes are mediated by TLR2 signalling, which activates NF- $\kappa \mathrm{B}$.

EGF binds to a homodimer or heterodimer receptor of EGFR to activate EGFR. Activated EGFR initiates underlying signalling pathways such as Ras/MAPK, Janus kinase/signal transducers and activators of transcription (JAK/STAT), and phosphatidylinositol 3-kinase/a serine/ threonine kinase. The activated signalling pathway is involved in the transcription of various genes, including $N F-k B^{27}$. Suppressor of cytokine signalling (SOCS) refers to a family of genes involved in inhibiting the JAK/STAT signalling pathway ${ }^{28}$. There are 8 members of the SOCS family; cytokine-inducible SRC homology 2 (SH2)-domain-containing protein and SOCS1-7 ${ }^{29}$. Recently, SOCS proteins have been involved in inflammatory responses of skin tissue. Expression level of SOCS3 protein is increased in peripheral blood mononuclear cells form patients with atopic dermatitis ${ }^{30}$, psoriatic lesional skin ${ }^{31}$. Interestingly, SOCS3 is induced during acute wound inflammation and remarkably, EGF induces SOCS3 MRNA expression in keratinocytes and murine primary keratinocytes ${ }^{32}$. Inferred from the references, it is speculated that SOCS proteins may be involved in these results that rhEGF inhibited cytokines expression and inhibition of NF- $\kappa \mathrm{B}$ activity. The further study is needed on the relation between inhibition effects of EGF on inflammatory responses and SOCS proteins.

In tumor cells, EGF activates NF- $\kappa \mathrm{B}$ related signalling pathways, and these signalling cascades are believed to crucially contribute to tumor development and progression $^{33}$. Thus, EGFR inhibitors, such as erlotinib and gefitinib, are being used as therapeutic agents for various types of cancer $^{34}$. However, cutaneous side effects are of-

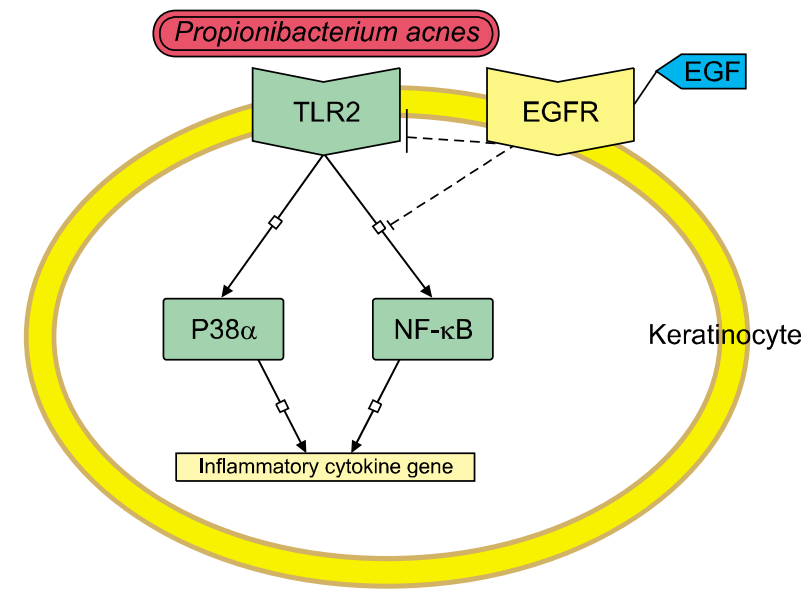

Fig. 5. Scheme of the pathway that mediates the epidermal growth factor (EGF)-induced inactivation of proinflammatory cytokines. TLR2: toll-like receptor 2, EGFR; EGF receptor, NF- $\kappa \mathrm{B}$ : nuclear factor kappa B.

ten observed in patients treated with EGFR inhibitors ${ }^{35}$. They include hair loss, acneiform eruption, paronychia and xerosis. EGFR inhibition enhances the production and release of proinflammatory mediators, and inhibits the production of antimicrobial peptides, resulting in the development of inflammatory papules and pustules as well as an impaired host defence function ${ }^{36,37}$. Interestingly, in this study, rhEGF also inhibits the expression of TLR2 and proinflammatory cytokines increased by $P$. acnes through the inhibition of NF- $\kappa \mathrm{B}$, which is restored by using gefitinib.

Our results indicate that EGF has an important role in the regulation of skin inflammation and immune responses through the suppression of NF- $\kappa \mathrm{B}$ activity in relation with TLR2/ NF- $\kappa \mathrm{B}$ signalling (Fig. 5). These findings, therefore, suggest the possible benefits of EGF in the treatment of acne and other inflammatory skin diseases.

\section{CONFLICTS OF INTEREST}

The authors have nothing to disclose.

\section{REFERENCES}

1. McInturff JE, Modlin RL, Kim J. The role of toll-like receptors in the pathogenesis and treatment of dermatological disease. J Invest Dermatol 2005;125:1-8.

2. Akira S, Uematsu S, Takeuchi O. Pathogen recognition and innate immunity. Cell 2006;124:783-801.

3. Shibata M, Katsuyama M, Onodera T, Ehama R, Hosoi J, Tagami H. Glucocorticoids enhance Toll-like receptor 2 expression in human keratinocytes stimulated with Propionibacterium acnes or proinflammatory cytokines. J Invest 
Dermatol 2009;129:375-382.

4. Li ZJ, Choi DK, Sohn KC, Seo MS, Lee HE, Lee Y, et al. Propionibacterium acnes activates the NLRP3 inflammasome in human sebocytes. J Invest Dermatol 2014;134:27472756.

5. Dispenza MC, Wolpert EB, Gilliland KL, Dai JP, Cong Z, Nelson AM, et al. Systemic isotretinoin therapy normalizes exaggerated TLR-2-mediated innate immune responses in acne patients. J Invest Dermatol 2012;132:2198-2205.

6. Selway JL, Kurczab T, Kealey T, Langlands K. Toll-like receptor 2 activation and comedogenesis: implications for the pathogenesis of acne. BMC Dermatol 2013;13:10.

7. Koff JL, Shao MX, Ueki IF, Nadel JA. Multiple TLRs activate EGFR via a signaling cascade to produce innate immune responses in airway epithelium. Am J Physiol Lung Cell Mol Physiol 2008;294:L1068-L1075.

8. Pastore S, Mascia F. Novel acquisitions on the immunoprotective roles of the EGF receptor in the skin. Expert Rev Dermatol 2008;3:525-527.

9. Wenczak BA, Lynch JB, Nanney LB. Epidermal growth factor receptor distribution in burn wounds. Implications for growth factor-mediated repair. J Clin Invest 1992;90:23922401.

10. Egger B, Carey HV, Procaccino F, Chai NN, Sandgren EP, Lakshmanan J, et al. Reduced susceptibility of mice overexpressing transforming growth factor alpha to dextran sodium sulphate induced colitis. Gut 1998;43:64-70.

11. Servold SA. Growth factor impact on wound healing. Clin Podiatr Med Surg 1991;8:937-953.

12. Kim HK, Yeo IK, Li K, Kim BJ, Kim MN, Hong CK. Topical epidermal growth factor for the improvement of acne lesions: a randomized, double-blinded, placebo-controlled, split-face trial. Int J Dermatol 2014;53:1031-1036.

13. Grange PA, Raingeaud J, Calvez V, Dupin N. Nicotinamide inhibits Propionibacterium acnes-induced IL-8 production in keratinocytes through the NF-kappaB and MAPK pathways. J Dermatol Sci 2009;56:106-112.

14. Miller LS, Sørensen OE, Liu PT, Jalian HR, Eshtiaghpour D, Behmanesh BE, et al. TGF-alpha regulates TLR expression and function on epidermal keratinocytes. J Immunol 2005; 174:6137-6143.

15. Bedford A, Chen T, Huynh E, Zhu C, Medeiros S, Wey D, et al. Epidermal growth factor containing culture supernatant enhances intestine development of early-weaned pigs in vivo: potential mechanisms involved. J Biotechnol 2015;196-197:9-19.

16. Mascia F, Mariani V, Girolomoni G, Pastore S. Blockade of the EGF receptor induces a deranged chemokine expression in keratinocytes leading to enhanced skin inflammation. Am J Pathol 2003;163:303-312.

17. Pastore S, Mascia F, Mariotti F, Dattilo C, Mariani V, Girolomoni G. ERK1/2 regulates epidermal chemokine expression and skin inflammation. J Immunol 2005;174: 5047-5056.

18. Valins W, Amini S, Berman B. The expression of toll-like receptors in dermatological diseases and the therapeutic effect of current and newer topical toll-like receptor modulators. J Clin Aesthet Dermatol 2010;3:20-29.

19. West AP, Koblansky AA, Ghosh S. Recognition and signaling by toll-like receptors. Annu Rev Cell Dev Biol 2006;22:409-437.

20. Pietrocola G, Arciola CR, Rindi S, Di Poto A, Missineo A, Montanaro L, et al. Toll-like receptors (TLRs) in innate immune defense against Staphylococcus aureus. Int J Artif Organs 2011;34:799-810.

21. Kim J, Ochoa MT, Krutzik SR, Takeuchi O, Uematsu $S$, Legaspi AJ, et al. Activation of toll-like receptor 2 in acne triggers inflammatory cytokine responses. J Immunol 2002; 169:1535-1541.

22. Bonizzi G, Karin M. The two NF-kappaB activation pathways and their role in innate and adaptive immunity. Trends Immunol 2004;25:280-288.

23. Kim H, Moon SY, Sohn MY, Lee WJ. Insulin-like growth factor-1 increases the expression of inflammatory biomarkers and sebum production in cultured sebocytes. Ann Dermatol 2017;29:20-25.

24. An $\mathrm{H}, \mathrm{Yu} Y$, Zhang $M, X u H$, Qi R, Yan $X$, et al. Involvement of ERK, p38 and NF-kappaB signal transduction in regulation of TLR2, TLR4 and TLR9 gene expression induced by lipopolysaccharide in mouse dendritic cells. Immunology 2002;106:38-45.

25. Anderson KV. Toll signaling pathways in the innate immune response. Curr Opin Immunol 2000;12:13-19.

26. Zhang G, Ghosh S. Toll-like receptor-mediated NF-kappaB activation: a phylogenetically conserved paradigm in innate immunity. J Clin Invest 2001;107:13-19.

27. Mendelsohn J, Baselga J. Status of epidermal growth factor receptor antagonists in the biology and treatment of cancer. J Clin Oncol 2003;21:2787-2799.

28. Yoshimura A, Naka T, Kubo M. SOCS proteins, cytokine signalling and immune regulation. Nat Rev Immunol 2007; 7:454-465.

29. Cooney RN. Suppressors of cytokine signaling (SOCS): inhibitors of the JAK/STAT pathway. Shock 2002;17:83-90.

30. Arakawa S, Hatano Y, Katagiri K. Differential expression of mRNA for Th1 and Th2 cytokine-associated transcription factors and suppressors of cytokine signalling in peripheral blood mononuclear cells of patients with atopic dermatitis. Clin Exp Immunol 2004;135:505-510.

31. Federici M, Giustizieri ML, Scarponi C, Girolomoni G, Albanesi C. Impaired IFN-gamma-dependent inflammatory responses in human keratinocytes overexpressing the suppressor of cytokine signaling 1. J Immunol 2002;169:434442.

32. Goren I, Linke A, Müller E, Pfeilschifter J, Frank S. The suppressor of cytokine signaling-3 is upregulated in impaired skin repair: implications for keratinocyte proliferation. J Invest Dermatol 2006;126:477-485.

33. Shostak K, Chariot A. EGFR and NF- $\kappa$ B: partners in cancer. Trends Mol Med 2015;21:385-393.

34. Baselga J, Swain SM. Novel anticancer targets: revisiting ERBB2 and discovering ERBB3. Nat Rev Cancer 2009; 9:463-475.

35. Hu JC, Sadeghi P, Pinter-Brown LC, Yashar S, Chiu MW. 
Cutaneous side effects of epidermal growth factor receptor inhibitors: clinical presentation, pathogenesis, and management. J Am Acad Dermatol 2007;56:317-326.

36. Lichtenberger BM, Gerber PA, Holcmann M, Buhren BA, Amberg N, Smolle V, et al. Epidermal EGFR controls cutaneous host defense and prevents inflammation. Sci
Transl Med 2013;5:199ra111.

37. Park K, Ommori R, Imoto K, Asada H. Epidermal growth factor receptor inhibitors selectively inhibit the expressions of human $\beta$-defensins induced by Staphylococcus epidermidis. J Dermatol Sci 2014;75:94-99. 